\title{
Centros de salud mental comunitaria: iSon la solución para los problemas de salud mental en el primer nivel de atención?
}

\section{Community mental health centers: Are the solution for mental health problems in primary care?}

\section{$\mathrm{DOI}$}

Milagros Calla-Torres ${ }^{1,2, a}$, María Hurtado-Ruiz, ${ }^{1,3, a}$,

https://doi.org/10.35434/rcmhnaaa.2021.142.1093

José Galvez-Olortegui ${ }^{1,4, b}$, César Li-Amenero ${ }^{5,6, c}$

Señor editor:

Los trastornos mentales son considerados un problema de salud debido a su prevalencia creciente y la carga de discapacidad que generan, superando a enfermedades crónicas como las cardiovasculares ${ }^{(1)}$. A pesar de esto, en las Américas se invierte solo el $2 \%$ del presupuesto nacional en Salud Mental (SM) ${ }^{(2)}$. En el Perú, el primer nivel de atención debería atender de manera integral a la mayor parte de la población; sin embargo, pese a la alta susceptibilidad de desarrollar trastornos mentales en pacientes con alguna patología, se prioriza la atención de enfermedades con problemas físicos ${ }^{(3)}$.

El año 2008 la Organización Mundial de la Salud (OMS) creó el Programa de Acción para Superar Brechas en Salud Mental (mhGAP), que propone la capacitación de médicos generales, enfermeros y técnicos de salud del primer nivel de atención, en el reconocimiento y la atención a personas con trastornos mentales ${ }^{(4)}$. Así mismo, la OMS creó el Plan de Acción sobre Salud Mental 2013-2020 ${ }^{(5)}$ para fomentar el cuidado de la SM desde el primer nivel de atención, a través del desarrollo de redes integrales de salud mental y de asistencia social de base comunitaria; aproximándose más a la comunidad.

En el Perú dichas medidas se han desarrollado progresivamente, llegando a la creación y la incorporación de los Centros de Salud Mental Comunitario (CSMC) al primer nivel de atención; ubicados en zonas desfavorecidas económicamente ${ }^{(6)}$. Su implementación, fortalecimiento y desarrollo ha sido impulsado por el Ministerio de Salud desde el año 2015, que gracias al soporte técnico y respaldo legal que se les ha proporcionado ${ }^{(7-8)}$, han permitido un incremento en la disponibilidad de recursos humanos y una mayor oferta de servicios de SM (tabla 1). No obstante, la brecha es grande y faltan medidas similares en otras instituciones prestadoras de servicios de salud (IPRESS) (EsSalud, Policía Nacional del Perú, Fuerzas Armadas y privados), así como una mayor difusión y conocimiento sobre la existencia de los CSMC, por la población y los profesionales de salud, acostumbrados a un enfoque de atención de los problemas de salud mental en hospitales psiquiátricos. Por ello, un modelo de atención comunitario, aun en desarrollo, no debería desvincularse completamente de los hospitales psiquiátricos. Por el contrario, un trabajo articulado y una retroalimentación permanente con dichos hospitales, aseguraría la asistencia de pacientes según capacidad resolutiva. A la espera que, la reforma de atención de la salud mental vaya consolidándose e implementando servicios asistenciales de atención de salud mental; con internamiento, como las Unidades de Hospitalización en Salud Mental y Adicciones; y servicios médicos de apoyo, como los hogares y residencias protegidos.

Los CSMC como núcleo del nuevo paradigma de atención en SM, representan el
FILIACIÓN

1. Unidad Generadora de evidencias y vigilancia epidemiológica, Scientia Clinical and Epidemiological Research Institute, Trujillo, Perú.

2. Facultad de Medicina Humana, Universidad Católica de Santa María, Arequipa, Perú.

3. Facultad de Medicina Humana, Universidad Nacional de Piura, Piura, Perú.

4. Servicio de Oftalmología, Hospital Universitario Central de Asturias, Oviedo, España.

. Unidad de Investigación Clínica, Scientia Clinical and Epidemiological Research Institute, Trujillo, Perú.

. Hospital Víctor Larco Herrera, Lima, Perú.

a. Estudiante de Medicina. b. Médico Cirujano, Magíster en Ciencias de la Investigación

Médico Cirujano, Especialista en Psiquiatría.

ORCID

1. Milagros Calla-Torres / 0000-0003-0328-876X

2. María Hurtado-Ruiz / / $10000-0001-6567-5592$

3. José Galvez-Olortegui / 0000-0003-1818-9801

4. César Li-Amenero / 0000-0002-8109-0583

\section{CORRESPONDENCIA}

César Li-Amenero
Dirección: Scientia Clinical and Epidemiological Research Dirección: Scientia Clinical and Epidemiological Research Institute. Mz. G Lt. 22 Urb. Vista Hermosa - Trujillo -
Telf. fijo: +51-44-626855, Telef. celular: 976505289.

EMAIL

cliamenero@scientiaceri.com

CONFLICTOS DE INTERÉS

Los autores declaramos no tener conflictos de interés.

\section{FINANCIAMIENTO}

Los autores declaramos no tener financiamiento para la realización de este estudio.

\section{REVISIÓN DE PARES}

Recibido: 05/05/2021

Aceptado: 30/06/202

\section{COMO CITAR}

Calla-Torres, M., Hurtado-Ruiz, M., Galvez-Olortegui, J., \& Li-Amenero, C. Centros de salud mental comunitaria: ¿Son la solución para los problemas de salud mental en el primer nivel de atención?. Revista Del Cuerpo Médico Hospital nivel de atencion?. Revista Del Cuerpo Médico Hospital
Nacional Almanzor Aguinaga Asenjo, 2021,14(2), 253 - 254. https://doi.org/10.35434/rcmhnaaa.2021.142.1093

sta obra está bajo una Licencia Creative Commons Atribución 4.0 Internacional.

Versión Impresa: ISSN: 2225-5109

Versión Electrónica: ISSN: 2227-4731

Cross Ref. DOI: 10.35434/rcmhnaaa

OJS: https://cmhnaaa.org.pe/ojs 
punto de partida para la atención en el primer nivel. Desde su creación, su desarrollo ha sido sostenido, aproximando la atención a las zonas más vulnerables; sin embargo, por las características culturales, sociales y políticas de nuestro país, presenta ciertas limitaciones. La heterogeneidad de nuestro territorio, demanda alternativas a los CSMC, que funcionen en paralelo o complementándolos. Entre ellas, podemos mencionar: el fortalecimiento de establecimientos del primer nivel con la presencia permanente o transitoria de especialistas en SM, además de los equipos multidisciplinarios existentes; la extensión de la iniciativa mhGAP y el acompañamiento clínico-psicosocial a otras IPRESS del primer nivel; la integración de la SM en otros programas de la salud sanitaria general; alianzas con otros sectores públicos, privados o mixtos en el abordaje de problemas de salud mental. Es decir, consolidar una red de salud mental como parte de una Red integrada de servicios de salud, donde los CSMC, aunque importantes, constituyen una de las varias alternativas que se podrían emplear en el primer nivel; en el contexto de un modelo comunitario de atención de salud mental.

En consecuencia, consideramos que los CSMC no son la única solución para los problemas de SM en el primer nivel, por lo que es importante evaluar la adecuada implementación de políticas nacionales de SM, que permitan desarrollar alternativas y construir redes de salud mental; acorde con la diversidad e idiosincrasia característica de cada localidad. Teniendo siempre presente que la falta de atención en SM, produce un impacto económico negativo, incrementa el riesgo de pobreza, desempleo y ausencia de educación; originando que la población no busque ni reciba ayuda $\operatorname{profesional}^{(9)}$.

Tabla 1. Las brechas en la salud mental en el Perú.

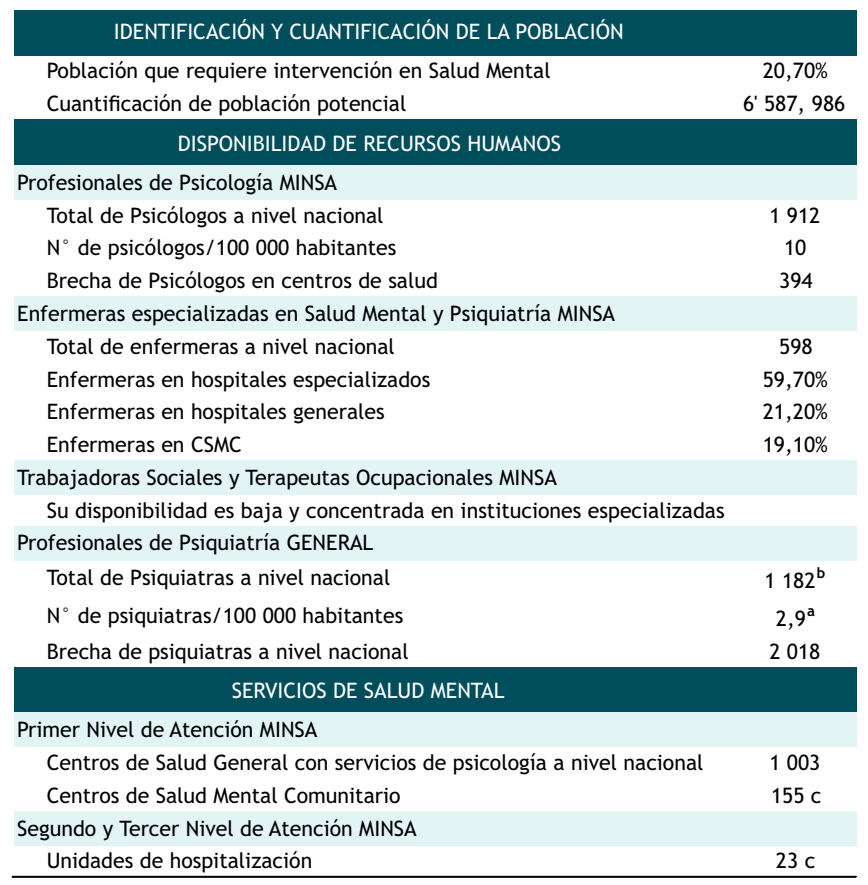

Fuente: Programa Presupuestal 0131 Control y Prevención en Salud Mental 2021 (Presenta últimos datos del MINSA correspondiente al año 2016)

Datos actualizados obtenidos de las páginas oficiales:

a. Organización Mundial de la Salud (OMS) 2016

https://apps. who.int/gho/data/node. main. MHHR?lang=en)

org.pe/conoce-a-tu-medicol

Ministerio de Salud (MINSA) 2020 (http: / www minsa. gob.pe/salud-mental/)

\section{REFERENCIAS BIBLIOGRÁFICAS}

1. Instituto Nacional de Salud Mental. Estudio Epidemiológico de Salud Mental en Hospitales Generales y Centros de Salud de Lima Metropolitana - 2015 - Informe General. Anales de Salud Mental 2018;34(1) [citado 3 de febrero de 2021]. Disponible en: http://www.insm.gob.pe/investigacion/estudios.html

2. Pan American Health Organization. Atlas of Mental Health of the Americas 2017. Washington, D.C.:PAHO; 2018 [citado 3 de febrero de 2021]. Disponible en: https://iris.paho.org/handle/10665.2/49664

3. Diez-Canseco F, Ipince A, Toyama M, Benate-Galvez Y, Galán-Rodas E, Medina-Verástegui JC, et al. Atendiendo la salud mental de las personas con enfermedades crónicas no transmisibles en el Perú: Retos y oportunidades para la integración de cuidados en el primer nivel de atención. Rev Peru Med Exp Salud Publica. 2014;31(1):131-6. D i s p o n i b l e

e $\mathrm{n}$ : http: / / www. scielo.org.pe/scielo.php?script=sci arttext\&pid=S1726 $-46342014000100019 \& \operatorname{lng}=\mathrm{es}$.

4. Organización Mundial de la Salud. mhGAP: Programa de acción para superar las brechas en salud mental: mejora y ampliación de la atención de los trastornos mentales, neurológicos y por uso de sustancias. Ginebra: OMS; 2009 [citado 3 de febrero de 2021]. Disponible en: https: //www.who.int/mental_health/mhgap/es/

5. Organización Mundial de la Salud. Plan de acción sobre salud mental 2013-2020. Ginebra: OMS, 2013 [citado 3 de febrero de 2021]. D i s p o n i b l e e n : https://www.who.int/mental_health/publications/action_plan/es I

6. Toyama M, Castillo H, Galea JT, Brandt LR, Mendoza M, Herrera V, et al. Peruvian mental health reform: A framework for scaling-up mental health services. In t J Health Policy Manag. 2017;6(9):501-8. doi: 10.15171/ijhpm.2017.07

7. Plan Nacional de Fortalecimiento de Servicios de Salud Mental Comunitaria 2017 - 2021 (RM N 356 - 2018/ MINSA) Ministerio de Salud Dirección General de Intervenciones Estratégicas en Salud Pública - Dirección de Salud Mental - Lima: Ministerio de Salud; 2018. 96 p. [citado 8 de febrero de 2021]. Disponible en: https: / / bibliotecavirtual.insnsb.gob.pe/plan-nacional-defortalecimiento-de-servicios-de-salud-mental-comunitaria-20182021-documento-tecnico/

8. Ley de Salud Mental. Ley N³0947. [citado 8 de febrero de 2021]. Disponible en: http://busquedas.elperuano.pe/normaslegales/leyde-salud-mental-ley-n-30947-1772004-1/

9. Morán-Mariños C, Alarcon-Ruiz CA, Alva-Diaz C. Pobreza y su influencia en el riesgo y daño familiar en un distrito de Lima, Perú: resultados por sectorización y atención primaria en salud. Med Fam SEMERGEN. 2019;45(4):225-31. doi: 10.1016/j.semerg.2019.02.007. 